\title{
Oxidative stress as determined by glutathione (GSH) concentrations in venous cord blood in elective cesarean delivery versus uncomplicated vaginal delivery
}

Orit Paamoni-Keren • Tali Silberstein • Ariela Burg • Iris Raz $\cdot$ Moshe Mazor · Oshra Saphier •

Adi Yekuda Weintraub

Published online: 3 August 2007

(C) Springer-Verlag 2007

Erratum to: Arch Gynecol Obstet (2007) 276:43-46

DOI 10.1007/s00404-006-0304-2

Due to an unfortunate error, the seventh author name was deleted. The complete list of author names is given below:

Orit Paamoni-Keren, Tali Silberstein, Ariela Burg, Iris Raz, Moshe Mazor, Oshra Saphier, and Adi Yekuda Weintraub.

The online version of the original article can be found under doi: 10.1007/s00404-006-0304-2.

O. Paamoni-Keren · T. Silberstein · I. Raz ·

M. Mazor · A. Y. Weintraub

Department of Obstetrics and Gynecology,

Soroka University Medical Center,

Faculty of Health Sciences,

Ben-Gurion University of the Negev,

Beer-Sheva, Israel

\section{A. Burg · O. Saphier $(\bowtie)$}

Department Chemical Engineering,

Faculty of Chemical Engineering,

Sami Shamoon College of Engineering,

Beer Sheva 84100, Israel

e-mail: oshras@sce.ac.il 